\title{
PENGEMBANGAN TRAINER EQUALIZER GRAFIS DAN PARAMETRIS SEBAGAI MEDIA PEMBELAJARAN MATA KULIAH PRAKTIK SISTEM AUDIO
}

\author{
Bekti Wulandari, Suparman, Djoko Santoso, Muslikhin, Athika Dwi Wiji Utami \\ Jurusan Pendidikan Teknik Elektronika, Fakultas Teknik Universitas Negeri Yogyakarta \\ E-mail: bektiwulandari@uny.ac.id
}

\begin{abstract}
The objectives of this study were to determine the development process of graphic and parametric equalizer trainer media in the course of Audio System and to examine the quality of the media. The development process of the media referred to the model offered by Lee and Owens. The research procedures consisted of assessment/analysis, designing, implementation and evaluation. The results of the study showed that the percentages for the quality aspect of the media and the companion module were 4.31 and 4.42 respectively. Based on these two aspects, it was obtained the overall percentage that was equal to 4.36. Whereas from the process of the trial by the students, the percentages of the media and the companion module were 4.47 and 4.36 respectively. Thus the level of validity and feasibility of the media was categorized as very good.
\end{abstract}

Keywords: Equalizer, Media, Module

\begin{abstract}
ABSTRAK
Penelitian ini bertujuan untuk mengetahui bagaimana pengembangan trainer equalizer grafis dan parametris sebagai media pembelajaran pada mata kuliah Sistem Audio serta bagaimana kelayakan trainer equalizer grafis dan parametris sebagai media pembelajaran pada mata kuliah Sistem Audio. Pengembangan media pembelajaran ini merujuk pada model yang ditawarkan oleh Lee dan Owens. Prosedur penelitian menggunakan tahapan asesmen/analisis, tahapan desain, tahapan implementasi dan tahapan evaluasi. Hasil penelitian menunjukkan bahwa perolehan persentase aspek kualitas media belajar sebesar 4,31, sedangkan untuk modul pendamping memperoleh skor 4,42. Berdasarkan kedua aspek tersebut dapat diperoleh persentase secara keseluruhan yaitu sebesar 4,36. Sedangkan dari uji coba pemakaian oleh mahasiswa media pembelajaran ini memperoleh skor penilaian media equalizer sebesar 4,47 dan untuk penilaian modul pendamping sebesar 4,36. Dengan demikian tingkat validasi dan tingkat kelayakan media dapat dikategorikan sangat baik.
\end{abstract}

Kata kunci: Equalizer, Media, Modul

\section{PENDAHULUAN}

Berdasarkan UU Sisdiknas tahun 2003, pendidikan kejuruan dan vokasi merupakan jenis pendidikan di Indonesia selain pendidikan umum. Perbedaan antara jenis-jenis pendidikan tersebut terletak pada karakteristiknya, misalnya karakteristik pendidikan umum yang lebih menekankan pada aspek teoritis di setiap proses pembelajaran, sedangkan pada pendidikan kejuruan dan vokasi lebih menekankan pada aspek praktis dibandingkan aspek teoritisnya. Hal tersebut terkait dengan tujuan luaran (output) yang diharapkan masing-masing jenis pendidikan berbeda satu dengan yang lain. Luaran pendidikan umum dipersiapkan untuk meneruskan pendidikan ke jenjang lebih tinggi, sedangkan pendidikan kejuruan dan vokasi berbeda. Walaupun lulusan pendidikan kejuruan dan vokasi juga dapat meneruskan pendidikan ke jenjang lebih lanjut, tetapi utamanya adalah lulusan yang siap kerja sesuai dengan keahlian yang ditempuh saat pendidikan tersebut.

Di Indonesia, pendidikan kejuruan dan vokasi diartikan secara berbeda. Perbedaan antara pendidikan kejuruan dan vokasi terletak 
pada jenjang pendidikannya. Dalam UU Sisdiknas tahun 2003, pendidikan kejuruan merupakan jenjang pendidikan menengah (SMK/MAK) yang mempersiapkan peserta didik terutama untuk bekerja dalam bidang tertentu. Sedangkan, pendidikan vokasi merupakan pendidikan tinggi yang mempersiapkan peserta didik untuk memiliki pekerjaan dengan keahlian terapan tertentu maksimal setara dengan sarjana. Contoh pendidikan vokasi adalah LPTK seperti UPI, UNNES, UNESA, UNY.

Berdasarkan tujuan keluaran, pendidikan kejuruan dan vokasi berproses dalam mempersiapkan dan membantu peserta didik dalam mengenali dirinya sesuai dengan tahapan perkembangan vokasional, mulai dari mengidentifikasi, mengeksplorasi, mempersiapkan, memilih, hingga pada tahapan peserta didik tersebut benar-benar menguasai satu keahlian tertentu pada suatu bidang pekerjaan sesuai dengan program keahlian yang ditempuhnya. Penguasaan keahlian peserta didik tersebut mencakup kemampuan dalam aspek kognitif, afektif, dan psikomotorik yang saling terintegrasi satu sama lain membentuk satu keahlian yang utuh terhadap sebuah bidang pekerjaan tertentu. Dalam mendukung hal tersebut, maka pada kegiatan proses pembelajaran, pendidikan kejuruan dan vokasi lebih diarahkan pada penumbuhan pengalaman belajar melalui rangsangan visual, kesadaran afektif, penggalian informasi kognitif, dan pengembangan keterampilan psikomotorik. Peraturan Pemerintah (PP) Nomor 19 Tahun 2005 tentang Standar Nasional Pendidikan Pasal 19 menjelaskan bahwa, "proses pembelajaran pada satuan pendidikan diselenggarakan secara interaktif, inspiratif, menyenangkan, menantang, memotivasi peserta didik untuk berpartisipasi secara aktif, serta memberikan ruang yang cukup bagi prakarsa, kreatifitas, dan kemandirian sesuai dengan bakat, minat, dan perkembangan fisik serta psikologis peserta didik". Seberapa besar dampak sebuah pendidikan/pembelajaran sangat tergantung dari seberapa banyak peserta didik dalam memperoleh pengalaman belajar (Putu Sudira, 2011). Selain pengalaman belajar, karakteristik individu peserta didik dan karakteristik kurikulum juga menjadi determinasi dampak belajar seorang peserta didik. Pembelajaran yang penuh dan kaya dengan pemberian pengalaman belajar akan memberi dampak besar dan positif terhadap peserta didik. Pengamalan belajar peserta didik sangat dipengaruhi oleh penampilan guru/ dosen, sarana dan prasarana belajar (learning resources equipment), suasana akademik dan lingkungan belajar, serta dukungan perangkat ICT (Putu Sudira, 2011).

Universitas Negeri Yogyakarta (UNY) sebagai salah satu bentuk lembaga pendidikan vokasi yang menyiapkan terbentuknya insan individu dengan keterampilan, kecakapan, pengertian, perilaku, sikap, kebiasaan kerja, dan apresiasi terhadap pekerjaan-pekerjaan yang dibutuhkan oleh masyarakat dunia usaha / industri, diawasi oleh masyarakat dan peme-rintah atau dalam kontrak dengan lembaga serta berbasis produktif (Putu Sudira, 2011). Fakultas Teknik merupakan satu dari tujuh fakultas yang dimiliki UNY. Fakultas Teknik memiliki 6 (enam) jurusan, salah satunya adalah Jurusan Pendidikan Teknik Elektronika. Visi Fakultas Teknik adalah pada tahun 2024 menjadi fakultas yang unggul di bidang pendidikan teknologi dan kejuruan berlandaskan ketakwaan, kemandirian, dan cendekia. Dalam pencapaian visi-visi tersebut, maka Fakultas Teknik memiliki beberapa misi, antara lain: (1) menyelenggarakan pendidikan akademik, profesi, dan vokasi dalam bidang pendidikan teknologi dan kejuruan yang didukung bidang non kependidikan untuk menghasilkan lulusan unggul berlandasarkan ketakwaan, kemandirian, dan kecendekiaan; (2) menyelenggarakan penelitian dasar dan terapan di bidang pendidikan dan keteknikan; (3) menyelenggarakan kegiatan pengabdian dan pemberdayaan pada masyarakat yang akan mendorong pengembangan potensi masyarakat dan lingkungan untuk mewujudkan kesejahteraan masyarakat; (4) menyelenggarakan tata kelola fakultas yang baik, bersih, dan akuntabel; dan (5) mengembangkan berbagai sumber daya 
dan kerjasama untuk mendukung pencapaian visi Fakultas Teknik.

Terkait dengan visi dan misi fakultas tersebut, maka peningkatan dampak belajar seorang peserta didik, mahasiswa, menjadi suatu keharusan dan kewajiban masing-masing jurusan, dalam hal ini Jurusan Pendidikan Teknik Elektronika. Salah satu upaya peningkatan dampak belajar mahasiswa adalah dengan mengoptimalkan komponen learning resources equipment dalam proses pembelajaran, baik pada mata kuliah teori maupun praktikum. Mata kuliah Sistem Audio merupakan salah satu mata kuliah yang wajib ditempuh mahasiswa program S1 Pendidikan Teknik Elektronika dan D3 Teknik Elektronika. Mata kuliah Sistem Audio mendeskripsikan dasar audio yang meliputi sistem audio, bunyi, kekuatan suara, sistem stereo, Hi-fi, distorsi, derau (noise), reverberation, akustik ruang, penguat audio yang meliputi penguat awal, penguat daya, pencampur (mixer), audio distribution, pengatur yang meliputi pengatur volume, pengatur loudness, pengatur nada, equalizer, pengatur balance loudspeaker yang meliputi macam loudspeaker, crossover mikrofon yang meliputi jenis dan prinsip kerja, kualitas, dan polar respon, tape recorder yang meliputi perekaman, main ulang, penghapusan rekaman, sistem mekanik, dolby, peredam noise, perekaman audio digital yang meliputi digital audio tape, compact disc, dan MP3. Kompetensi mahasiswa yang diharapkan diantaranya adalah kemampuan secara kognitif dan psikomotrik, antara lain: (1) mendeskripsikan dasar audio yang meliputi sistem audio, bunyi, kekuatan suara, sistem stereo, Hi-fi, distorsi, derau (noise), reverberation, akustik ruang (2) mendeskripsikan karakteristik penguat audio; (3) mendeskripsikan karakteristik equalizer; (4) mendeskripsikan prinsip kerja dan karakteristik loudspeaker; (5) mendeskripsikan prinsip kerja dan karakteristik mikrofon; (6) mendeskripsikan fungsi cross-over; (7) mendeskripsikan perekaman, main ulang, dan penghapusan rekaman pada tape recorder; (8) mendeskripsikan sistem mekanik pada tape recorder; dan (10) mendeskripsikan sistem audio digital.

Pembelajaran merupakan kegiatan penyampaian informasi yang diciptakan untuk memfasilitasi pencapaian tujuan yang spesifik. Untuk memudahkan proses pembelajaran tidak terlepas dari faktor lingkungan yang tidak terbatas pada konteks tempat. Hal ini dinyatakan oleh Heinich et.al. (2005: 7), "Instruction is the arrangement of information and environment to facilitate learning." Lingkungan dapat berupa model, metode, strategi, media, dan atau sarana yang dibutuhkan untuk memfasilitasi proses belajar siswa. Berdasarkan hasil observasi, diketahui bahwa media yang digunakan dalam proses pembelajaran praktikum mata kuliah Sistem Audio masih bersifat konvensional, misalnya pada materi equalizer, media praktikum yang dipergunakan masih berupa komponen lepas yang harus dirangkai terlebih dahulu oleh para mahasiswa. Hal ini tentu membuat proses pembelajaran menjadi kurang efektif dan efisien. Diperlukan waktu yang yang lebih lama dalam persiapan sebelum mahasiswa melakukan praktikum. Maka dari itu, perlu adanya upaya perbaikan dalam proses pembelajaran tersebut dalam kaitannya dengan pengoptimalan dampak belajar yang dihasilkan.

Salah satu bentuk upaya perbaikan tersebut adalah dengan melakukan pengembangan media pembelajaran praktikum berupa trainer. Harapan dengan dikembangkannya media pembelajaran trainer tersebut adalah agar mahasiswa dapat mempelajari materi pada mata kuliah Sistem Audio dengan lebih mudah, efektif, dan efisien. Media pembelajaran trainer yang akan dikembangkan berfokus pada materi equalizer grafis dan parametris yang mencakup fungsi equalizer dalam mengatur intensitas suara dalam ruang audio. Kegiatan penelitian pengembangan ini dimulai dari tahapan mendesain, merancang, membuat, dan menguji kelayakan media.

Model pengembangan merupakan tahapan atau langkah-langkah yang dilakukan dalam pengembangan. Model pengembangan yang menjadi acuan dalam melakukan penelitian 
pengembangan, salah satunya merujuk pada model yang ditawarkan oleh Lee dan Owens (2004). Model Lee dan Owens diadopsi untuk menekankan tahapan implementasi pada model dengan memasukkan white box testing dan black box testing. White box testing merupakan sebuah metode uji program/produk dimana desain/ struktur/implementasi dari produk tersebut diketahui oleh penguji. Perbedaan dengan black box testing adalah pada metode ini, desain/ struktur/implementasi dari produk tersebut tidak diketahui oleh pengujinya.

Model pengembangan lain yaitu model Hannafin dan Peck (1988) yang menawarkan dalam tiga tahapan, yaitu: (1) need assessment; (2) desain; dan (3) pengembangan beserta evaluasi. Letak evaluasi dan revisi pada model Hannafin dan Peck terletak pada tiap tahapan. Model Alessi dan Trollip (2001: 13) membagi ke dalam tiga tahap: (1) planning; (2) design; dan (3) development. Beberapa model tersebut lebih cenderung pada R\&D pengembangan media/ multimedia pembelajaran termasuk model Lee dan Owens (2004).

\section{METODE}

Penelitian ini menggunakan prosedur Research and Development karena hasil akhir penelitian berorientasi pada suatu produk. Apabila produk tersebut telah mendapat validasi serta pengakuan ahli melalui uji alfa, kemudian uji beta dan selanjutnya dievaluasi pada pembelajaran di kelas sesungguhnya (Alessi dan Trolip, 2001). Pengembangan trainer ini merujuk pada model yang ditawarkan oleh Lee dan Owens (2004) yang digabung dengan model Pressman (2010). Dipilih model Pressman, karena model ini cenderung pada pengembangan software engineering dibanding multimedia pembelajaran. Model pengembang- an Pressman diadopsi untuk memperkuat tahap pengembangan pada model Lee dan Owens dengan memasukkan prosedur white box testing, dan black box testing, dimana terletak pada spiral 3 dan 4 .

Penelitian dan pengembangan dilakukan secara bertahap, untuk tahap asesmen/analisis, tahap desain dan tahap pengembangan dilakukan melalui survei awal pada September s/d Desember 2013. Tahap selanjutnya adalah survei lanjutan, untuk tahap ini peneliti terjun ke lapangan sudah dilengkapi instrumen yang valid. Pelaksanan survei dilakukan pada bulan MaretApril 2014 di tempat yang sama. Tahap implementasi (uji beta) dilakukan pada Mei s/d Oktober 2014 di laboratorium Elektronika Dasar Jurusan Pendidikan Teknik Elektronika UNY. Fase evaluasi dilakukan melalui penyelenggaraan pembelajaran di laboratorium yang sama.

Penelitian ini menggunakan dua subyek coba yaitu subyek coba uji beta dan subyek coba tahap evaluasi. Subyek coba tersebut adalah mahasiswa yang mengikuti mata kuliah Sistem Audio di Jurusan Teknik Elektronika. Subyek Coba Uji Beta dan Evaluasi adalah mahasiswa dari Jurusan Pendidikan Teknik Elektronika.

Pelaksanaan Research and Development terdiri dari dua prosedur yang digunakan yaitu penelitian dan pengembangan. Prosedur penelitian menggunakan tahap asesmen/analisis dan tahap evaluasi, sedangkan prosedur pengembangan berisi tahap desain, tahap pengembangan dan tahap implementasi. Prosedur pengembangan trainer yang dilakukan dalam penelitian ini melalui beberapa tahapan pengembangan seperti yang ditunjukkan pada Gambar 1 di bawah ini. 


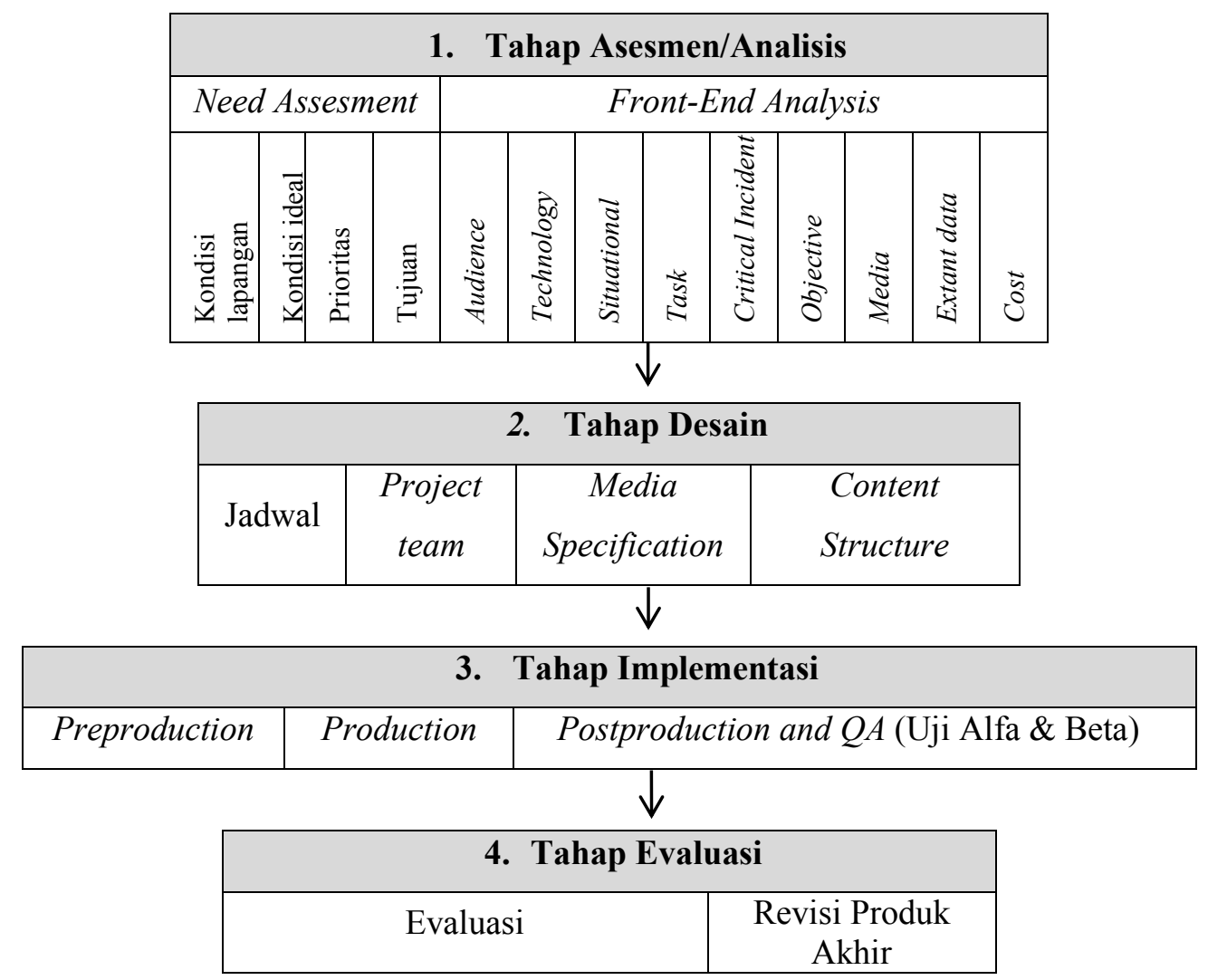

Gambar 1. Prosedur R\&D Model Lee dan Owens (2004)

Penelitian ini meliputi dua kegiatan, yaitu pengembangan produk media pembelajaran equalizer dan evaluasi yang memerlukan instrumen yang spesifik. Instrumen untuk pengembangan produk, menggunakan; (a) angket untuk tahap need assessment and analysis; (b) angket untuk mengukur hasil uji alfa; dan (c) angket untuk mengukur hasil uji beta. Instrumen pengumpul data untuk evaluasi dilakukan menggunakan angket evaluasi.

Metode analisis data yang digunakan dalam menjawab permasalahan adalah teknis analisis deskriptif kuantitatif dan evaluatif. Teknik ini digunakan karena dalam penelitian R\&D tidak melakukan uji hipotesis. Tahap pertama, penelitian menguji kelayakan produk hardware yang digunakan dalam mata kuliah Sistem Audio di Jurusan Pendidikan Teknik Elektronika. Teknis analisis deskriptif dilakukan untuk menentukan kelayakan media dalam fungsinya. Tahap kedua, fokus penelitian pada evaluasi media pembelajaran equalizer untuk proses menentukan metode pelatihan pada pengguna. Dalam kuesioner diberikan lima alternatif pilihan untuk memberikan tanggapan tentang media yang dikembangkan, yaitu; sangat baik dengan skor 5 , baik dengan skor 4 , cukup baik dengan skor 3, kurang baik dengan skor 2, dan sangat kurang baik dengan skor 1 .

\section{HASIL DAN PEMBAHASAN}

Hasil penelitian dan pengembangan ini berupa produk Equalizer Parametris dan Grafis yang mampu membantu dosen dalam pembelajaran mata kuliah praktik Sistem Audio. Sebelum dilakukan pengembangan, diawali dengan penelitian sebagai dasar pengembangan produk. Keberhasilan produk terletak pada tahap pengembangan yang ditumpu pada dua tahap sebelumnya, tahap asesmen/analisis dan desain. Bagian asesmen/analisis berfungsi menjembatani antara kondisi lapangan dan kondisi ideal.

Need Assessment and Analysis (NAA) dilakukan untuk memperoleh berbagai kebutuhan yang diperlukan guna mengembangkan 
media pembelajaran equalizer sesuai dengan keinginan pengguna. Hal tersebut fokus pada identifikasi dan mendapatkan data mengenai kebutuhan yang diperlukan dalam perancangan dan pengembangan equalizer mencakup aspek: prioritas, pengguna, teknologi, situasional, fungsi, tujuan, hingga biaya. Proses NAA dilakukan terhadap beberapa mahasiswa Jurusan Pendidikan Teknik Elektronika melalui survei dalam kurun waktu 5 Juli s/d 5 Agustus 2014, hasilnya dapat diketahui hal-hal seperti yang disajikan pada Tabel 1.

Tabel 1. Hasil NAA yang Dilakukan terhadap Mahasiswa D3 Teknik Elektronika

\begin{tabular}{llcc}
\hline \multirow{2}{*}{ No. } & \multicolumn{2}{c}{ Indikator yang dinilai } & \multicolumn{2}{c}{ Frekuensi } \\
& & Ya & Tidak \\
\hline N1 & Pernah mendapat mata kuliah Audio & 24 & 0 \\
N2 & Pernah mendapat materi equalizer & 24 & 0 \\
N4 & Dosen menggunakan metode tertentu & 14 & 10 \\
N5 & Dosen menggunakan media equalizer & 24 & 0 \\
N6 & Dalam pembelajaran disertai labsheet/modul & 24 & 0 \\
N7 & Pernah mendapat materi equalizer grafis & 24 & 0 \\
N8 & Pernah mendapat materi equalizer parametris & 0 & 24 \\
\hline
\end{tabular}

Diagram batang untuk hasil NAA yang dilakukan terhadap mahasiswa D3 Teknik Elektronika dapat disajikan dalam Gambar 2 berikut ini.

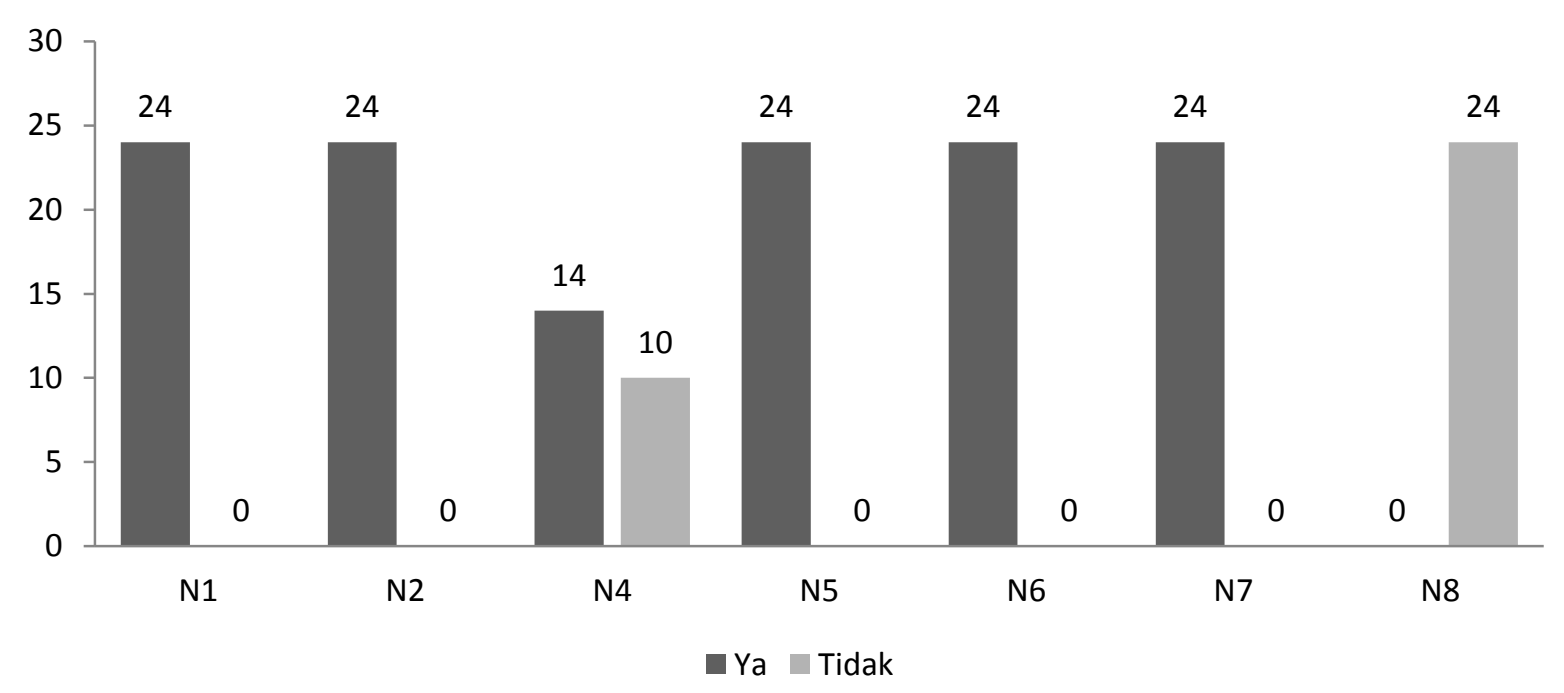

Gambar 2. Diagram Batang Hasil NAA

Hal lain yang menjadi fokus pengungkapan fakta lapangan adalah mengenai pembelajaran mata kuliah Sistem Audio materi equalizer telah diberikan pada semester 3 untuk mahasiswa D3 Teknik Elektronika dan di semester 4 untuk mahasiswa S1 Pendidikan Teknik Elektronika. Dari hasil wawancara terungkap bahwa untuk mahasiswa pada mata kuliah Sistem Audio hanya mendapat materi equalizer grafis, sedangkan equalizer parametris belum pernah diperoleh.

Selanjutnya dilakukan validasi oleh ahli media. Validasi ahli ini untuk memperoleh kelayakan media dan digunakan sebagai hasil pengembangan media equalizer. Ahli memvalidasi dua instrumen yakni media equalizer dan modul. Untuk media equalizer terdiri dari 5 aspek; content, navigation, performance, com- 
patibility dan security kemudian dikembangkan menjadi 22 butir pertanyaan. Sedangkan dari modul equalizernya sendiri terdapat empat aspek yaitu: kelayakan sajian, kelayakan isi, kelayakan tata bahasa, dan kelayakan grafik yang dikembangkan menjadi 25 butir pertanyaan. Ahli memberi saran dan komentar untuk perbaikan butir pertanyaan.
Uji alfa equalizer dilakukan dengan memberi input dan melihat hasil outputnya melalui percobaan laboratorium. Uji alfa sendiri mengacu pada Allesssi dan Pressman. Pengujian ini fokus pada kinerja sistem secara komprehensif, ada enam test case yang dilakukan secara berulang-ulang. Adapun hasil uji tersaji dalam Tabel 2.

Tabel 2. Data Hasil Test Case Media Pembelajaran Equalizer

\begin{tabular}{|c|c|c|c|c|}
\hline Test Case & Skenario Pengujian & Hasil yang Diharapkan & $\begin{array}{l}\text { Hasil } \\
\text { Pengujian }\end{array}$ & Simpulan \\
\hline 01 Power & $\begin{array}{l}\text { Tombol "power" } \\
\text { ditekan }\end{array}$ & $\begin{array}{l}\text { Trainer posisi standby dan } \\
\text { siap digunakan }\end{array}$ & $\begin{array}{l}\text { Sesuai } \\
\text { harapan }\end{array}$ & Valid \\
\hline $\begin{array}{l}02 \text { Input } \mathrm{EQ} \\
\text { diberi } \mathrm{AFG}\end{array}$ & $\begin{array}{l}\text { Memberi input pada } \\
\text { jack RCA }\end{array}$ & $\begin{array}{l}\text { Equalizer akan } \\
\text { menampilkan sinyal input } \\
\text { pada CRO }\end{array}$ & $\begin{array}{l}\text { Sesuai } \\
\text { harapan }\end{array}$ & Valid \\
\hline $\begin{array}{l}03 \text { Output EQ } \\
\text { dihubungkan } \\
\text { dengan CRO }\end{array}$ & $\begin{array}{l}\text { Membaca output pada } \\
\text { jack RCA }\end{array}$ & $\begin{array}{l}\text { Equalizer akan } \\
\text { menampilkan output pada } \\
\text { CRO }\end{array}$ & $\begin{array}{l}\text { Sesuai } \\
\text { harapan }\end{array}$ & Valid \\
\hline $\begin{array}{l}04 \text { Ch diatur } \\
\text { posisi cut }\end{array}$ & $\begin{array}{l}\text { Channel 1-10 } \\
\text { diposisikan "cut" }\end{array}$ & $\begin{array}{l}\text { Out pada CRO akan terlihat } \\
\text { penurunan output }\end{array}$ & $\begin{array}{l}\text { Sesuai } \\
\text { harapan }\end{array}$ & Valid \\
\hline $\begin{array}{l}05 \text { Ch diatur } \\
\text { posisi boost }\end{array}$ & $\begin{array}{l}\text { Channel 1-10 } \\
\text { diposisikan "boost" }\end{array}$ & $\begin{array}{l}\text { Out pada CRO akan terlihat } \\
\text { penguatan output }\end{array}$ & $\begin{array}{l}\text { Sesuai } \\
\text { harapan }\end{array}$ & Valid \\
\hline $\begin{array}{l}06 \text { Mencoba } \\
\text { panel Ch }\end{array}$ & $\begin{array}{l}\text { Terjadi pengaturan } \\
\text { cut/boost }\end{array}$ & $\begin{array}{l}+ \text { kanan/atas } \\
\text {-kiri/down }\end{array}$ & $\begin{array}{l}\text { Kadang } \\
\text { terbalik cut- } \\
\text { /boost }+\end{array}$ & Revisi \\
\hline
\end{tabular}

*) Format pengujian diadaptasi dari Pressman, 2010: 530.

Tujuan lain dilakukannya uji alfa adalah untuk melakukan validasi produk equalizer baik grafis maupun parametris dengan menggunakan angket. Sebelumnya instrumen uji alfa telah divalidasi oleh dua validator. Uji alfa dilakukan pada 20 Oktober 2014 melalui percobaan di Laboratorium Audio. Uji alfa yang dilaksanakan oleh tim penguji dilakukan dengan mencoba fungsi dan memberi penilaian melalui angket yang sudah disiapkan. Hasil pengujian ditunjuk- kan pada gambar 3 di bawah ini. Berdasarkan Gambar 3 tersebut dapat diketahui besaran persentase untuk masing-masing indikator yang dilakukan pada uji alfa. Aspek dalam pengujian ini adalah: content, navigation, performance, compatibility dan security. Kriteria penilaian terdiri dari tiga kategori yaitu: CB (ckup baik), B (baik), dan SB (sangat baik). 


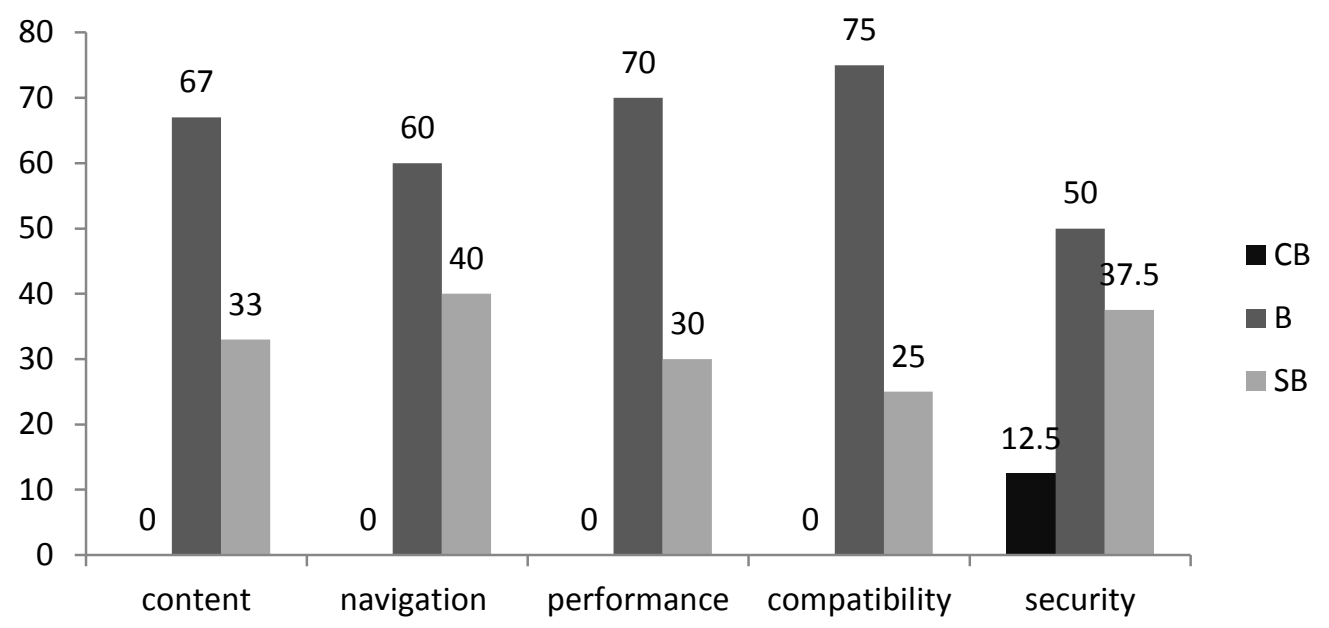

Gambar 3. Persentase Hasil Uji Alfa Equalizer

Aspek content dalam uji alfa juga menilai aspek function/fungsi yang di dalamnya ada 6 indikator. Uji alfa pada aspek ini, fokus pengujian adalah pada kemampuan equalizer misalnya: tata letak, ukuran dan bentuk tulisan, penempatan tulisan keterangan, minimalisir ambiguitas. Hasil uji alfa berikutnya menilai aspek navigation yang di dalamnya ada 5 indikator. Uji alfa pada aspek navigation, pengujian fokus pada navigasi panel equalizer misalnya: pemisahan trainer equalizer grafik dan parametris, penempatan panel-panel, kemudahan penyambungan socket pada trainer, penempatan pin (jumper).

Hasil uji alfa berikutnya menilai aspek performance yang di dalamnya ada 5 indikator. Uji alfa pada aspek performance, pengujian fokus pada performa/kinerja equalizer unjuk kerja trainer sesuai dengan kompetensi, kestabilan trainer, kualitas perancangan, daya tarik tampilan, dan tingkat kemudahan. Uji alfa untuk berikutnya menilai aspek compatibility, didalamnya ada 2 indikator. Hal yang fokus diuji kompatibel dengan sistem audio lain dapat dihubungkan dengan sistem pengeras suara. Uji alfa yang terakhir adalah aspek security, dalam aspek ini ada 4 indikator yang dinilai. Aspek security, difokuskan pada keamanan media misalnya: resiko sengatan listrik, kebocoran daya, keamanan pin out dan keamanan selain sengatan listrik. Selain media equalizer, modul pendamping equalizer (praktikum) juga dilakukan uji alfa. Diagram batang prosentase uji alfa untuk modul yang terbagi dalam 4 aspek terlihat dalam Gambar 4 di bawah ini.

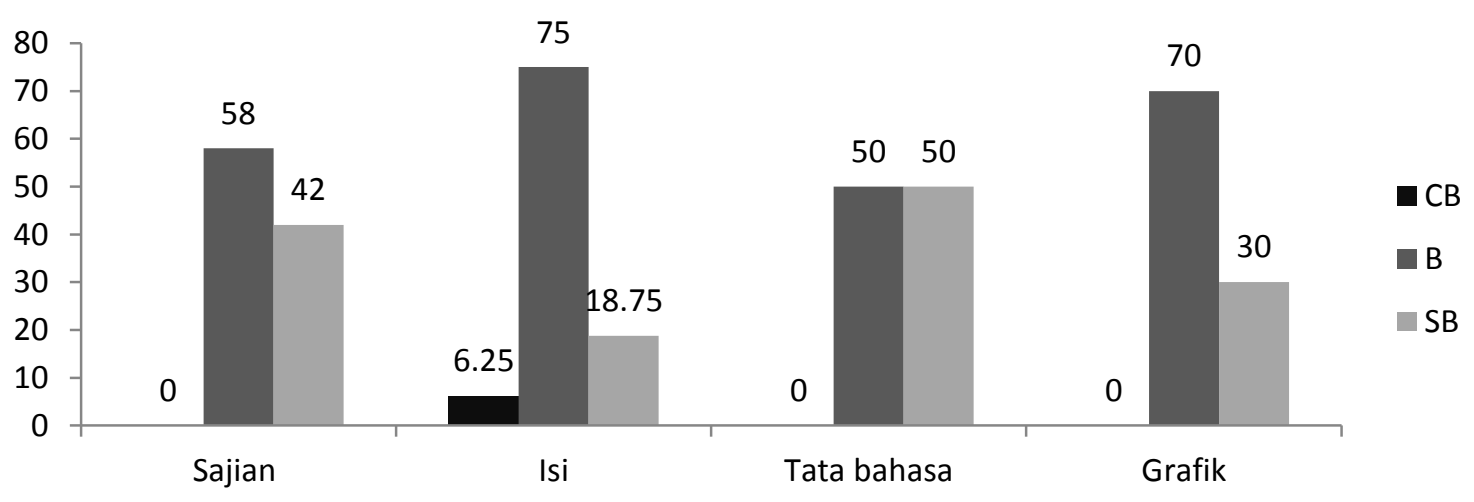

Gambar 4. Persentase Uji Alfa Modul 
Media dan modul equalizer harus lolos uji alfa sebelum dilakukan uji beta. Uji beta dilakukan pada mahasiswa jurusan Pendidikan Teknik Elektronika hal ini dipilih dengan asumsi bahwa responden pernah mendapat mata kuliah tersebut sebelumnya.

Pemilihan responden tersebut dilakukan secara acak. Hasil uji beta disajikan pada Tabel 5 di bawah ini. Data uji beta diperoleh melalui angket yang diberikan, responden uji beta setelah mencoba media dan modul equalizer. Hasil uji beta yang dilakukan pada responden masing-masing dilakukan pada Jumat, 17 Oktober 2014. Mahasiswa melakukan praktikum menggunakan media dengan panduan sesuai modul dan kemudian mengisi angket yang menilai dari bagian content, navigation, performance, compability, dan security dari media tersebut.

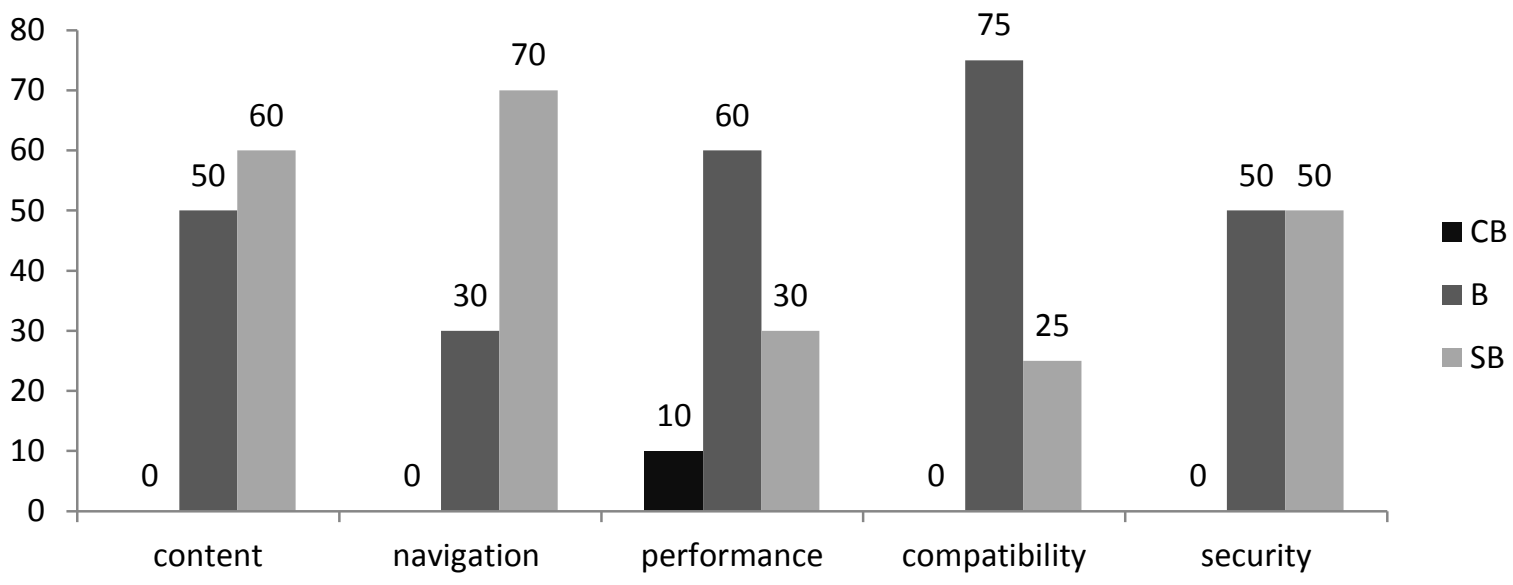

Gambar 5. Persentase Hasil Uji Beta

Aspek content dalam uji beta di dalamnya ada 6 indikator. Uji beta pada aspek ini fokus pengujian pada kemampuan equalizer misalnya: tata letak, ukuran dan bentuk tulisan, penempatan tulisan keterangan, minimalisir ambiguitas. Hasil uji beta berikutnya menilai aspek navigation yang di dalamnya ada 5 indikator. Uji beta aspek navigation, pengujian fokus pada navigasi panel equalizer misalnya; pemisahan trainer equalizer grafik dan parametris, penempatan panel-panel, kemudahan penyambungan socket pada trainer, penempatan pin (jumper). Selain media equalizer, modul pendamping equalizer (praktikum) juga dilakukan uji beta dan hasilnya seperti Gambar 6 berikut.

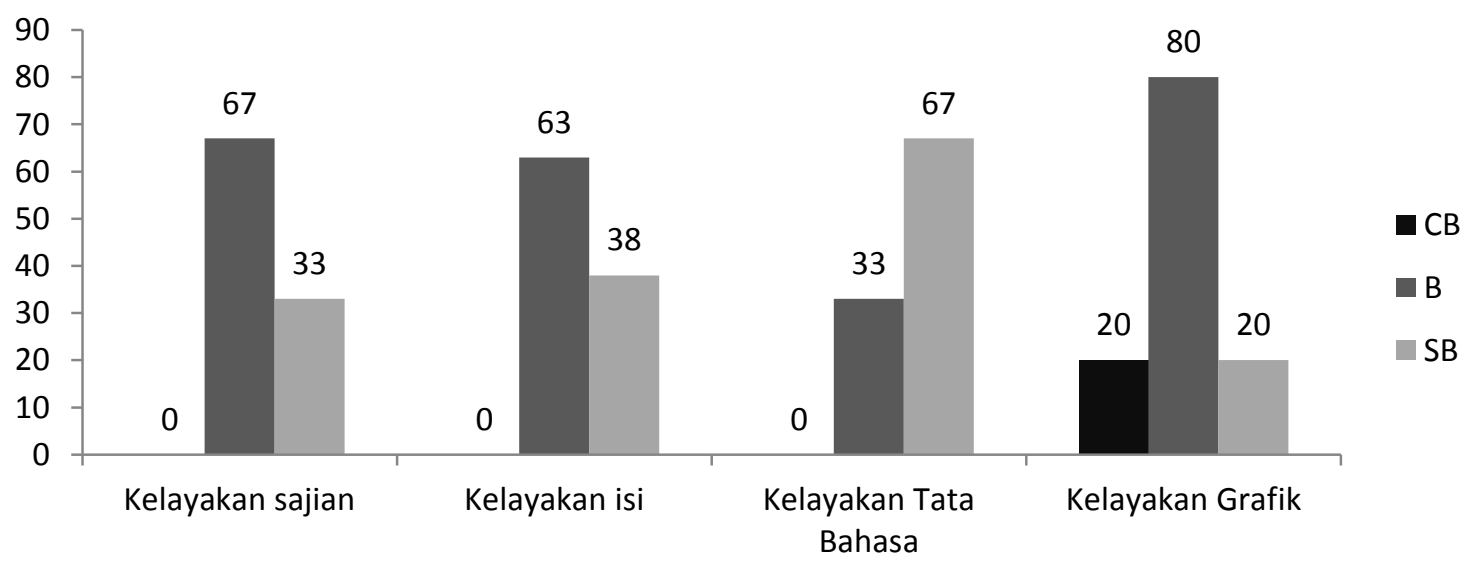

Gambar 6. Persentase Hasil Uji Beta Modul Equalizer 
Data hasil evaluasi penggunaan media equalizer sebagai media pembelajaran mata kuliah Sistem Audio. Evaluasi dilaksanakan di Laboratorium TV terhadap 6 mahasiswa D3 Teknik Elektronika dan 4 mahasiswa S1 Pendidikan Teknik Elektronika. Selain data penilaian, pada tahap evaluasi ini dilakukan penilaian hasil berdasarkan Opinion-Based Evaluation atau dikenal dengan evaluasi berbasis pendapat. Ada 8 indikator yang menjadi bahan Opinion-Based Evaluation (OBE) lebih cenderung pada evaluasi hasil penggunaan modul yang dilakukan mahasiswa sebagai user. Hasil penilaian OBE tersaji pada Tabel 3.

Tabel 3. Hasil Opinion Based Evaluation Media Pembelajaran Equalizer

\begin{tabular}{llccccc}
\hline No. & \multicolumn{1}{c}{$\begin{array}{c}\text { Opinion Based Evaluation } \\
\text { Indikator yang Dinilai }\end{array}$} & SKB & KB & CB & B & SB \\
& $\quad \mathbf{1}$ & $\mathbf{2}$ & $\mathbf{3}$ & $\mathbf{4}$ & $\mathbf{5}$ \\
\hline O1 & Waktu dihabiskan dengan baik & 0 & 1 & 1 & 4 & 1 \\
O2 & Materi relevan bagi keilmuan saya ke depan & 0 & 0 & 0 & 2 & 6 \\
O3 & Media berguna bagi saya & 0 & 1 & 3 & 8 & 2 \\
O4 Modul menarik bagi saya & 0 & 2 & 4 & 4 & 3 \\
O5 Urutan penyajianmembangkitkan saya belajar & 0 & 0 & 3 & 5 & 4 \\
O6 Penyampaian materijelas & 0 & 0 & 2 & 3 & 1 \\
Frekuensi & 0 & 4 & 13 & 26 & 17 \\
Jumlah (skala x frekuensi) & 0 & 8 & 39 & 104 & 85 \\
Total Penilaian & & & 236 & & \\
Rerata Penilaian & & & 3.93 & & \\
\hline
\end{tabular}

Melihat hasil dari test-case Tabel 3, maka dapat disimpulkan bahwa media equalizer valid dan layak digunakan. Hal ini terlihat dari hasil pengujian modul equalizer yang sebagian besar sesuai dengan yang diharapkan. Dalam pengembangan modul ini ada revisi pada pengaturan panel Ch. Revisi ini dilakukan agar pada saat pengaturan $\mathrm{cut} /$ boost tidak terbalik antara kutub positif dan negatifnya. Sedangkan kategori kelayakan media adalah sangat layak yang diperoleh dari hasil rata-rata uji alfa yang memperoleh persentase sebesar 4.3\%. Dan tingkat validasi media pembelajaran ini dikategorikan sangat baik dilihat dari uji beta yang memeperoleh persentase $4.42 \%$.

Pengembangan modul equalizer dapat dilakukan melalui beberapa tahap, yaitu tahap analisis/asesmen, tahap desain, tahap implementasi, dan tahap evaluasi. Tahap analisis/ asesmen ini dilakukan sebagai proses untuk menentukan hasil, mengindentifikasi kesenjangan antara kondisi saat ini dengan kondisi yang diinginkan. Dari tahap ini terlihat bahwa mahasiswa jurusan Pendidikan Teknik Elektronika hanya mendapat materi equalizer grafis sedangkan equalizer parametris belum pernah diperoleh sehingga diperlukan pengembangan media equalizer.

Trainer equalizer ini dirancang sesuai dengan kompetensi dasar yang ingin dicapai dalam praktikum. Trainer equalizer ini terdiri dari equalizer grafis dan parametris yang tidak saling terkait sehingga dalam penggunaannya dapat digunakan secara bergantian. Trainer equalizer grafis dirancang agar mahasiswa dapat memahami dan mengamati adanya respon frekuensi pada posisi boost dan cut. Sedangkan equalizer parametris dirancang agar mahasiswa dapat dengan mudah memahami dan mengamati perubahan tegangan output pada setiap chanel low, mid, dan high.

Untuk mempermudah dalam penggunaan trainer equalizer ini maka didampingi dengan sebuah modul panduan yang menjelaskan mengenai teori-teori equalizer baik equalizer grafis maupun parametris. Modul menjelaskan lang- 
kah-langkah dalam melakukan praktikum menggunakan trainer equalizer tersebut agar dapat berjalan sesuai dengan tujuan dan tidak terjadi kesalahan ketika melakukan praktikum.

Berdasarkan hasil pengujian melalui testcase diperoleh beberapa pengujian dengan hasil yang sesuai yang diharapkan. Pada enam testcase yang dicoba, ada satu test-case yang gagal (perlu perbaikan). Ini artinya media equalizer dapat digunakan dengan cacatan memperbaiki hasil temuan test-case yang mengalami gagal.

Dalam tahap implementasi yang digunakan untuk mendapatkan data tingkat kelayakan media pembelajaran dilakukan dengan cara uji kelayakan dari dosen ahli media, dosen ahli materi yang disebut dengan uji alfa. Selanjutnya dilakukan uji beta yaitu uji pada sisi pengguna yaitu mahasiswa. Uji alfa bertujuan mengidentifikasi dan menghilangkan sebanyak mungkin masalah sebelum akhirnya sampai ke pengguna. Pengujian dilakukan setelah media pembelajaran equalizer selesai dikembangkan oleh orangorang yang tidak terlibat dalam pengembangan dan memang ahli di bidangnya. Instrumen uji alfa diperlukan untuk menjamin kevalidan hasil kinerja media pembelajaran equalizer. Berdasarkan hasil penelitian perolehan persentase aspek kualitas media sebesar $4.31 \%$, sedangkan untuk modul pendamping memperoleh $4.42 \%$. Dari kedua aspek tersebut didapatkan persentase keseluruhan yaitu sebesar $4.36 \%$. Dengan demikian tingkat kelayakan trainer equalizer sebagai media pembelajaran dapat dikategorikan sangat baik.

Uji beta dilakukan oleh calon pengguna dan pengguna diberitahukan prosedur uji beta, lalu diminta memberi penilaian terhadap media pembelajaran equalizer untuk memperoleh datanya. Uji beta media pembelajaran berasal dari mahasiswa Jurusan Pendidikan Teknik Elektronika. Dari uji coba pemakaian oleh mahasiswa media pembelajaran ini memperoleh penilaian media equalizer sebesar $4.47 \%$ dan untuk penilaian modul pendamping sebesar $4.36 \%$. Dengan demikian tingkat validasi media pembelajaran ini dapat dikategorikan sangat baik dilihat dari uji beta (pengguna mahasiswa).

\section{SIMPULAN}

Berdasarkan hasil penelitian dan pembahasan yang telah dikemukakan, maka diperoleh simpulan sebagai berikut: (1) Proses pengembangan trainer equalizer sebagai media pembelajaran pada mata kuliah Sistem Audio adalah: (a) mengumpulkan potensi dan masalah, peneliti menemukan masalah belum dikembangkannya serta terbatasnya media pembelajaran untuk praktik mahasiswa khususnya praktikum equalizer grafis dan parametris; (b) melakukan pengumpulan data dan literatur guna menunjang penelitian ini: (c) melakukan desain produk, pengembangan produk yang meliputi menentukan kompetensi dasar, menganalisis kebutuhan pengembangan trainer, membuat desain trainer equalizer grafis dan parametris, membuat instrumen untuk menilai kelayakan trainer, melakukan validasi dan melakukan ujicoba untuk mengetahui kelayakan trainer; dan (2) Berdasarkan hasil penelitian perolehan persentase aspek kualitas media sebesar 4,31\%, sedangkan untuk modul pendamping memperoleh sebesar 4,42\%. Dari kedua aspek tersebut didapatkan persentase keseluruhan yaitu sebesar $4.36 \%$. Dengan demikian tingkat kelayakan trainer equalizer sebagai media pembelajaran dikategorikan sangat baik. Sedangkan dari uji coba pemakaian oleh mahasiswa media pembelajaran ini memperoleh penilaian media equalizer sebesar $4,47 \%$ dan untuk penilaian modul pendamping sebesar $4.36 \%$. Dengan demikian tingkat validasi media pembelajaran ini dikategorikan sangat baik dilihat dari uji beta (pengguna mahasiswa). Berdasarkan data tersebut dapat disimpulkan bahwa trainer equalizer sebagai media pembelajaran pada praktik Sistem Audio di Jurusan Pendidikan Teknik Elektronika layak digunakan untuk proses pembelajaran. 


\section{DAFTAR RUJUKAN}

Alessi, S. M. and Trollip, S. R. 2001. Multimedia for Learning: Methods and Development $3^{r d}$ ed. Massachusetts: Allyn and Bacon

Hannafin, M. J. and Peck, K. L. 1988. The Design, Development, And Evaluation of Instruction Software. New York: MacMiillan Publishing Company

Heinich R., Molenda, M., Russel, J.D., et al. 2005. Instructional Media and TechNologies for Learning $\left(8^{\text {th }} e d\right)$. New Jersey: Prentice Hall

Lee, W. and Owens, D. L. 2004. Multimedia Based Instructional Design: Computer
Based Training Web Based Training Distance Broadcast Training, Performance Based Solutions $2^{\text {nd }}$ ed. San Fransisco: Pfeiffer

Pressman, R. S. 2010. Software Engineering: $A$ Practitioner's Approach, $7^{\text {th }} \mathrm{ed}$. New York: Mc Graw Hill

Putu Sudira. 2011. Kurikulum dan Pembelajaran Pendidikan dan Pelatihan Vokasi Menyongsong Skill Masa Depan. Makalah Pengembangan Kurikulum. Bali: Politeknik Negeri Bali 